\title{
The role of interleukin-2 and interleukin-4 in disease progression in patients with schistosomiasis combined with chronic viral hepatitis $\mathrm{C}$ and chronic viral hepatitis $B$
}

Nasser Mousa, Ilham Talat qattan, Ahmed Abdel-Razik,Tarek sheta, Hassan Rizk, Atef Elshazly, Ahmed Deiab, Farha Elshinawy.

\section{Summary}

Background: Schistosomiasis remains an important cause of parasitic morbidity and mortality worldwide. In countries where schistosomiasis is endemic, a high prevalence of combined Schistosomiasis mansoni and chronic hepatitis $C$ and chronic hepatitis $B$ co-infection has been described. The immunopathogenesis of human schistosomiasis with or without chronic hepatitis remains controversial. Aim of the work: Is to evaluate the immunopathogenic role of Th1 cytokine (IL-2) and Th2 cytokine (IL-4) in patients with different stages of hepatointestinal schistosomiasis with or without chronic hepatitis. Methods: The study included 60 Egyptian patients with different stages of hepatointestinal schistosomiasis. They include 40 patients with hepatosplenic schistosomiasis (divided into 4 subgroups according to stage of hepatosplenic schistosomiasis), 10 patients with schistosoma mansoni and chronic hepatitis $C$ and 10 patients with schistosoma mansoni and chronic hepatitis $B$ co-infection, In addition to, 10 healthy controls. IL-2 and II-4 was measured by competitive enzyme immunoassay (EIA) which measures the natural and recombinant forms of the cytokines. Results: Compared to control group, patients with hepatosplenic schistosomiasis showed significant increase in serum IL-2 from stage $1(P<0.05)$ to stage $4(P<0.001)$. Moreover, both groups with combined schistosomiasis and chronic hepatitis $C$ and chronic hepatitis $B$ showed significant increase in the $I L-2(P<0.05$ for both). Furthermore, decompensated schistosomiasis showed highly significant increase in the IL-2 versus compensated schistosomiasis $(P<0.001)$. Also, compared to control group, patients with hepatosplenic schistosomiasis showed significant increase in serum IL-4, that decreased from stage $1(P<0.001))$ to nonsignificant increase in stage $4(P>0.05)$. In addition, chronic HCV with schistosomiasis showed significant increase in the IL-4 $(P<$ 0.05 ) and chronic HBV with schistosomiasis showing significant increase in the $I L-4(P<0.001)$. Moreover, compensated schistosomiasis showed significant increase in the IL-4 $(P<0.001)$ versus decompensated schistosomiasis. Conclusion: Patients with chronic schistosomiasis present a mixed profile of Th1 and Th2 cytokines. The Th1 (IL-2) was increased with the progression of the hepatosplenic schistosomiasis from stage 1(hepatomegaly) to the stage 4. However, The Th2 (IL-4) was elevated in the first stage of hepstosplenic schistosomiasis and then decreased with progression of the disease. In patients with combined schistosomiasis and chronic hepatitis the Th2 (IL-4) is the predominant cytokine versusTh1 (IL-2).

Keywords: Schistosomiasis, chronic hepatitis, interleukin-2 and interleukin-4

\author{
Medical Journal of Viral Hepatitis \\ (MJVH) 2019; 3 (2) - pp. 57-64
}

Received: $18 / 12 / 2018$

Revised: $8 / 1 / 2019$

Accepted: 20/1/2019

Published Online: 25/4/2019

(Nasser Mousa, Ahmed Abdel-Razik) Tropical Medicine dept, Faculty of Medicine, Mansoura Univ., Egypt.

(IIham Talat qattan) Medical Molecular Virology, Taibah University, KSA

(Tarek sheta, Hassan Rizk, Ahmed Deiab) Internal Medicine dept., Faculty of Medicine, Mansoura Univ., Egypt.

(Atef Elshazly) Parasitology dept., Faculty of Medicine, Mansoura Univ., Egypt.

(Farha Elshinawy) Clinical pathology dept., ., Faculty of Medicine, Mansoura Univ., Egypt.

* CA: Nasser Mousa

mousa medic@yahoo.com

\section{Introduction}

Human schistosomiasis is one of the most harmful parasitic diseases. It is reported to be endemic in 77 countries in tropical and subtropical regions, leading to infection of about 250 million individuals universal ${ }^{1}$. Schistos- omiasis is a disease caused predominantly by the host's immune response to schistosoma ova and the granulomatous reaction they induce ${ }^{1-6}$. The granulomas destroy the eggs and sequester or neutralize otherwise pathogenic egg antigens 
but also leads to fibrogenesis in host tissues ${ }^{6}$. An effective $\mathrm{T}$-cell response is known to be essential for the development of the granulomatous response and host survival ${ }^{7}$. Studies in human patients of the association between disease severity and the production of cytokines have shown that, different clinical forms of schistosomiasis are associated with distinct immunological profiles ${ }^{\mathbf{8 , 9}}$. Moreover, studies proposed that, the outcome of human schistosomiasis is influenced by the nature of the Th1/Th2 immune response against schistosome antigens ${ }^{10}$. Yet, there is no strong consensus about the pattern of cytokine production and regulation that causes severe hepatosplenic (HS) disease, which is characterized by periportal fibrosis and portal hypertension. HS disease and the progression of hepatic fibrosis are associated with the production of profibrotic type 2 cytokines in the early stages of infection with schistosoma mansoni. But, other studies demonstrated that, HS disease is characterized by a predominant $\mathrm{T}$ helper 1 profile ${ }^{11}$. Concurrent infection between hepatitis $\mathrm{B}$ virus (HBV) and schistosomiasis is well known in countries where schistosomiasis is endemic and might cause chronic liver inflammation ${ }^{\mathbf{1 2}}$. S. mansoni and HBV co-infection pathogenesis remains debated; however, the harmful effects of S. mansoni and hepatitis $\mathrm{C}$ virus (HCV) co-infection on liver fibrosis have confirmed

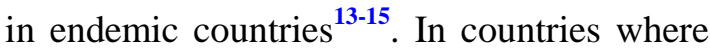
schistosomiasis is endemic for example Egypt, a high prevalence of $\mathrm{HBV}$ and $\mathrm{S}$. mansoni coinfection has been described ranging from 19.6 to $33.0 \%{ }^{16,17}$. Similarly, published data about HCV and schistosomiasis co infection is scanty. Prevalence rates of $\mathrm{HCV}$ infection with wide variations as low as $1 \%$ and as high as $50 \%$ among patients with schistosomiasis, were reported in many countries ${ }^{18,19}$. Likewise high $(40.2 \%)$ prevalence of $\mathrm{HCV}$ and $\mathrm{S}$. mansoni antibodies were in some study ${ }^{20}$. Interestingly, a study among 3,596 Egyptian patients found that $27.3 \%$ had both HCVRNA and schistosomiasis, though a weak point is their reliance on serology to diagnose schistosomiasis, a thing that questions the association between $\mathrm{HCV}$ and schistosomia$\operatorname{sis}^{21}$. Our aim is to study the impact of IL-2 and IL-4 in-patient with chronic schistosomiasis and hepatitis $\mathrm{B}$ or $\mathrm{C}$ co-infection.

\section{Subjects and Methods Patients}

This study was carried out on 70 Egyptian cases attending clinics of Tropical Medicine and
Internal Medicine Departments (inpatient and outpatient) Mansoura university Hospital. They include 40 patients with hepatosplenic schistosomiasis (20 males and 20 females), 10 patients with chronic HCV infection (8 males and 2 females) and 10 patients with chronic HBV infection (6 males and 4 females). In addition to, 10 healthy control ( 5 males and 5 females), mean age in years was (37.30 \pm 15.20$)$. The studied cases were classified into 4 groups:

Group 1: Cases of hepatosplenic schistosomaiasis include 40 patients who are further classified into four subgroups according to stages of hepatosplenic schistosomiasis ${ }^{22}$. Group 1-A: Hepatosplenic schistosomiasis stage 1 (Hepatomegaly), include 10 patients (4 males and 6 females) with mean age in years (39.10 $\pm 13.12)$. Group 1-B: Hepatosplenic schistosomiasis stage 2 (Hepatosplenomegaly) include 10 patients ( 3 males and 7 females) with mean age in years $(40.20 \pm 12.91)$. Group $1-C$ : Hepatosplenic schistosomiasis stage 3 (splenomegaly with shrunken liver), include 10 patients (7 males and 3 females) with mean age in years (38.20 \pm 10.71$)$. Group 1-D: Hepatosplenic schistosomiasis stage 4 (Decompensated schistosomiasis), include 10 patients (6 males and 4 females) with mean age in years (41.80 $\pm 9.86)$. Patients with schistosomiasis were also classified again according to clinical stage into: Compensated schistosomiasis: (without ascites), include 30 patients (14 males and 16 females) with mean age (39.15 \pm 12.58 ). Decompensated schistosomiasis: (with ascites) include 10 patients (6 males and 4 females) with mean age in years $(41.80 \pm 9.86)$.

Group 2: Cases of schistosomiasis with chronic hepatitis $\mathrm{C}$ virus include 10 patients $(8$ males and 2 females) with mean age in years $(41.80$ $\pm 18.1095)$.

Group 3: Cases of schistosomiasis with chronic hepatitis $B$ virus include 10 patients ( 6 males and 4 females) with mean age in years (42.20 $\pm 8.1486)$. Control group, include 10 patients (5 males and 5 females) with mean age in years $(37.30 \pm 15.2032)$.

Group 4: 10 healthy control (5 males and 5 females), mean age in years was (37.30 \pm 15.20 )

\section{Exclusion criteria}

Autoimmune diseases, diabetes mellitus, malignancies, hematological diseases, allergic skin diseases, connective tissue or collagen diseases, cardiovascular diseases, kidney diseases, bac- 
terial or fungal diseases, and other parasitic diseases. All patients and control groups were subjected to the following; thorough history taking, clinical examination and abdominal ultrasography. The study was carried out in accordance with the guidelines of the Helsinki Declaration.

\section{Laboratory investigations}

Included; liver functions (transaminases serum bilirubin, albumin, prothrombin time), serum creatinine, complete blood picture and stool and urine examination. Viral markers (HAV, HBV, HCV and HIV) were screened by ELIZA technique- Kits were provided by Abbott Diagnostic). Stool culture, rectal snip biopsies were done. Interlukin-2 and Interlukin-4 were measured by ACCUCYTE human IL-2 and IL-4 (cytimmune Sciences Inc.), a competitive enzyme immunoassay (EIA), which measures the natural and recombinant forms of the cytokines IL-2 and IL-4.

\section{Statistical analysis}

Statistical analysis was done by SPSS (statistical package for social science) program version 10 . The qualitative data were presented in the form of number and percentage. Chisquare test was used as a test of significance for qualitative data. The quantitative data were presented in the form of mean, standard deviation. Student t-test was used as a test of significance for quantitative data.

\section{Results}

This study was carried out on 70 Egyptian patients. They include 40 patients with hepatosplenic schistosomiasis with mean age in years (39.90 \pm 13.12$), 10$ patients with chronic $\mathrm{HCV}$ infection with mean age in years (41. $80 \pm 18.10)$ and 10 patients with chronic HBV infection with mean age in years $(42.20$ $\pm 8.14)$. In addition to, 10 healthy control with mean age in years was $(37.30 \pm 15.20)$, tab. (1). Table (2) shows the laboratory data of the studied groups. As regarding the serum albumin, patients with hepatosplenic schistosomiasis showed gradual decreasing form stage 1 where was the mean value $(4.01 \mathrm{~g} / \mathrm{dl})$ down to the stage 4 (decompensated schistosomiasis) where was the mean value $(2.27 \mathrm{~g} / \mathrm{dl})(\mathrm{p}=\mathrm{P}<0.001)$. In both groups of schistosomiasis with chronic hepatitis there was, decrease in serum albumin, where the mean value in chronic hepatitis $\mathrm{C}$ with schistosomiasis was $(2.36 \mathrm{~g} / \mathrm{dl})$ and in chronic hepatitis B was $(2.14 \mathrm{~g} / \mathrm{dl})(\mathrm{p}=\mathrm{P}<0$. 001 for both groups). As regard the serum bilirubin, all hepatosplenic schistosomiasis showing non-significant increase. However, in both groups of schistosomiasis with chronic hepatitis there was significant increase in both groups where, the mean value in chronic hepatitis $\mathrm{C}$ with schistosomiasis was $(1.6 \mathrm{mg} / \mathrm{dl})$ and in chronic hepatitis B was $(1.7 \mathrm{mg} / \mathrm{dl})$ ( $\mathrm{P}<0.001$ for both groups). As regard the ALT and AST levels, all hepatosplenic schistosomiasis showed non-significant increase. However, in both groups of schistosomiasis with chronic hepatitis there was significant increase in both groups where the mean value was in chronic hepatitis $\mathrm{C}$ with schistosomiasis (61.2 $\mathrm{Iu} / \mathrm{l})$ and in chronic hepatitis B $(52.2 \mathrm{Iu} / \mathrm{L})$. Concerning AST levels in both groups of schistosomiasis with chronic hepatitis, there was significant increase in both groups where the mean value was in chronic hepatitis $\mathrm{C}$ with schistosomiasis $(60.8 \mathrm{Iu} / \mathrm{l})$ and in chronic hepatitis B (55.8 In/l). Table (3) shows the significance of the IL-2 (Th1) in the studied groups versus the control group. Compared to control group, patients with hepatosplenic schistosomiasis showed significant increase in serum IL-2, stage $1(\mathrm{P}<0.05)$, stage $2(\mathrm{P}<0.01)$, stage $3(\mathrm{P}<0.01)$ and stage $4(\mathrm{P}<0.001)$. Moreover, Chronic HCV with schistosomiasis showed a significant increase in the IL-2 $(\mathrm{P}<0.05)$ and chronic HBV with schistosomiasis showed significant increase in the IL-2 $(\mathrm{P}<0.05)$. Table (4) shows the significance of the IL-4 (Th2) in the studied groups versus the control group. Compared to control group, patients with hepatosplenic schistosomiasis showed significant increase in serum IL-4, stage $1(\mathrm{P}<0.001))$, stage $2(\mathrm{P}<0.001))$, stage $3(\mathrm{P}<0.01)$ while, hepatosplenic schistosomiasis stage 4 showing non-significant increase in the IL-4 $(\mathrm{P}>0.05)$. Furthermore, chronic HCV with schistosomiasis showed significant increase in the IL-4 $(\mathrm{P}<$ $0.05)$ and chronic HBV with schistosomiasis showing significant increase in the IL-4 $(\mathrm{P}<$ 0.001). Furthermore, decompensated schistosomiasis showed highly significant increase in the IL-2 versus compensated schistosomiasis ( $\mathrm{P}<0.001)$ fig. (1). However, compensated schistosomiasis showed significant increase in the IL-4 versus decompensated schistosomiasis ( $\mathrm{P}<0.001)$ fig. (2). 
Table (1) The age and sex distribution of studied groups

\begin{tabular}{lcccc}
\multicolumn{1}{c}{ Group } & $\begin{array}{c}\text { Hepatosplenic } \\
\text { schistosomiasis } \\
\mathbf{N = 4 0}\end{array}$ & $\begin{array}{c}\text { Chronic HCV and } \\
\text { schistosomiasis } \\
\mathbf{N = 1 0}\end{array}$ & $\begin{array}{c}\text { Chronic HBV and } \\
\text { schistosomiasis } \\
\mathbf{N = 1 0}\end{array}$ & $\begin{array}{c}\text { Control } \\
\mathbf{N = 1 0}\end{array}$ \\
$\begin{array}{l}\text { Age/ year } \\
\begin{array}{l}\text { Gender: } \\
\text { male/female }\end{array}\end{array}$ & $39.90 \pm 13.12$ & $41.80 \pm 18.10$ & $42.20 \pm 8.14$ & $37.30 \pm 15.20$ \\
\hline
\end{tabular}

$\boldsymbol{P}=0.069$ for age distribution, and $\boldsymbol{P}=0.169$ for sex distribution

Table (2) Laboratory data of studied groups

\begin{tabular}{lcccc}
\multicolumn{1}{c}{ Stages of Hepatosplenomegaly } & Bilirubin & ALT & AST & Albumin \\
Hepatosplenomegaly stage 1 & $0.831 \pm 0.10$ & $29.71 \pm 2.60$ & $35.20 \pm 2.41$ & Mean \pm SD \\
Hepatosplenomegaly stage 2 & $0.86 \pm 0.10$ & $35.21 \pm 3.12$ & $33.120 \pm 3.32$ & $3.95 \pm 0.12$ \\
Hepatosplenomegaly stage 3 & $0.87 \pm 0.10$ & $36.12 \pm 3.21$ & $34.21 \pm 4.99$ & $3.93 \pm 0.41$ \\
Hepatosplenomegaly stage 4 & $1.00 \pm 0.17$ & $33.70 \pm 3.56$ & $32.20 \pm 4.09$ & $2.27 \pm 0.22$ \\
Chronic HCV with schistosomiasis & $1.69 \pm 0.45$ & $61.20 \pm 9.30$ & $60.80 \pm 12.34$ & $2.36 \pm 0.29$ \\
Chronic HBV with schistosomiasis & $1.75 \pm 0.27$ & $52.20 \pm 4.93$ & $55.80 \pm 10.68$ & $2.14 \pm 0.10$ \\
\hline
\end{tabular}

Table (3): IL-2 $\mathrm{ng} / \mathrm{ml}$ of the studied groups

\begin{tabular}{lccc}
\hline \multicolumn{1}{c}{ Groups } & Mean \pm SD & P value \\
\hline Hepatosplenic schistosomiasis: stage 1 & $190.23 \pm 20.91$ & $<0.05$ \\
\hline Hepatosplenic schistosomiasis: stage 2 & $230.12 \pm 50.12$ & 0.01 \\
\hline Hepatosplenic schistosomiasis: stage 3 & $310.91 \pm 96.17$ & 0.01 \\
\hline Hepatosplenic schistosomiasis: stage 4 & $367.1 \pm 12.91$ & 0.001 \\
\hline Chronic HCV and schistosomiasis & $255 \pm 16.91 .0$ & $<0.05$ \\
\hline Chronic HBV and schistosomiasis & $267.15 \pm 25.12$ & $<0.05$ \\
\hline Control group & $167.6 \pm 70.67$ & \\
\hline
\end{tabular}

$\boldsymbol{P}$ value versus control group

Table (4): IL-4 $\mathrm{ng} / \mathrm{ml}$ of the studied groups

\begin{tabular}{lcc}
\multicolumn{1}{c}{ Groups } & Mean \pm SD & P value \\
\hline Hepatosplenic schistosomiasis: stage 1 & $360.12 \pm 60.12$ & $\mathrm{P}<0.001$ \\
\hline Hepatosplenic schistosomiasis: stage 2 & $340.17 \pm 70.14$ & $\mathrm{P}<0.001$ \\
\hline Hepatosplenic schistosomiasis: stage 3 & $287.12 \pm 69.12$ & $\mathrm{P}<0.01$ \\
\hline Hepatosplenic schistosomiasis: stage 4 & $250.1 \pm 99.1$ & $\mathrm{P}>0.05$ \\
Chronic HCV and schistosomiasis & $467.4 \pm 109.9$ & $\mathrm{P}<0.05$ \\
Chronic HBV and schistosomiasis & $436.1 \pm 63.18$ & $\mathrm{P}<0.001$ \\
\hline Control & $202.1 \pm 42.21$ & \\
\hline
\end{tabular}

$\boldsymbol{P}$ value versus control group 


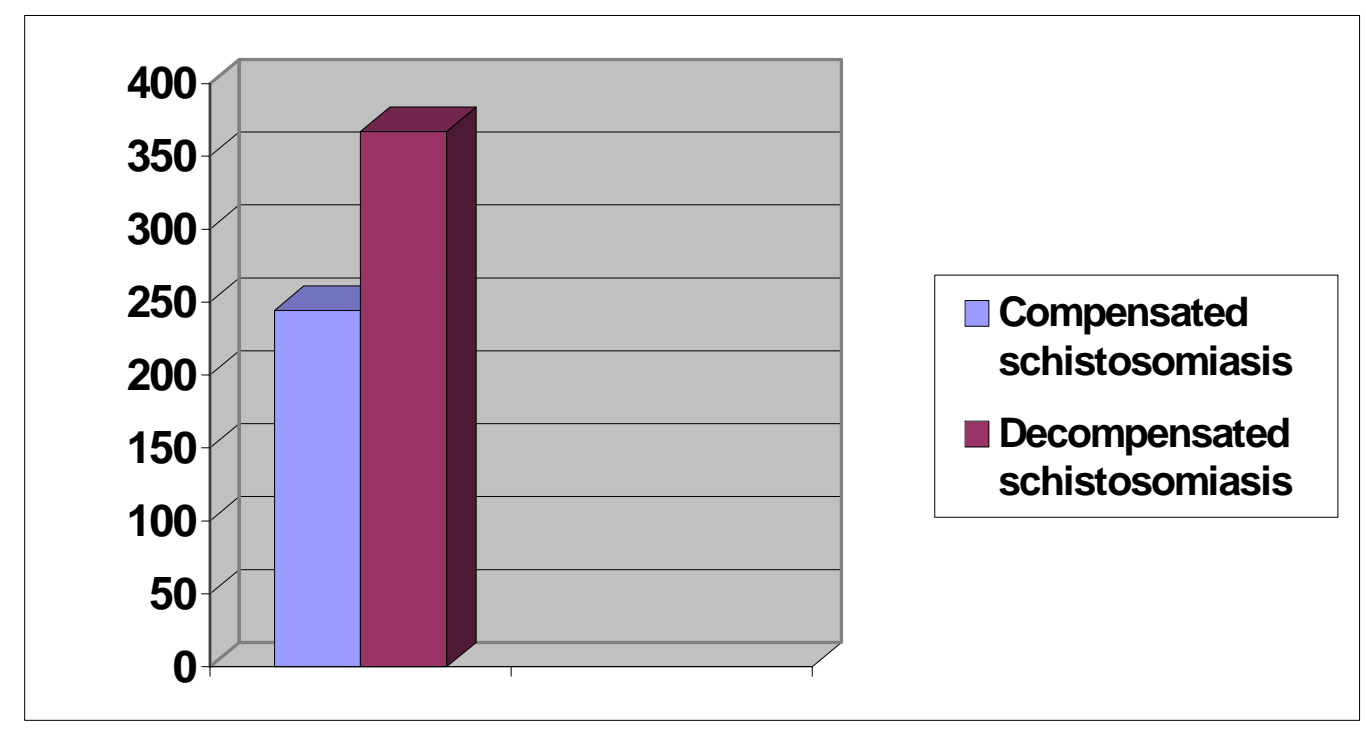

Figure (1) IL-2 in compensated and decompensated schistosomiasis.

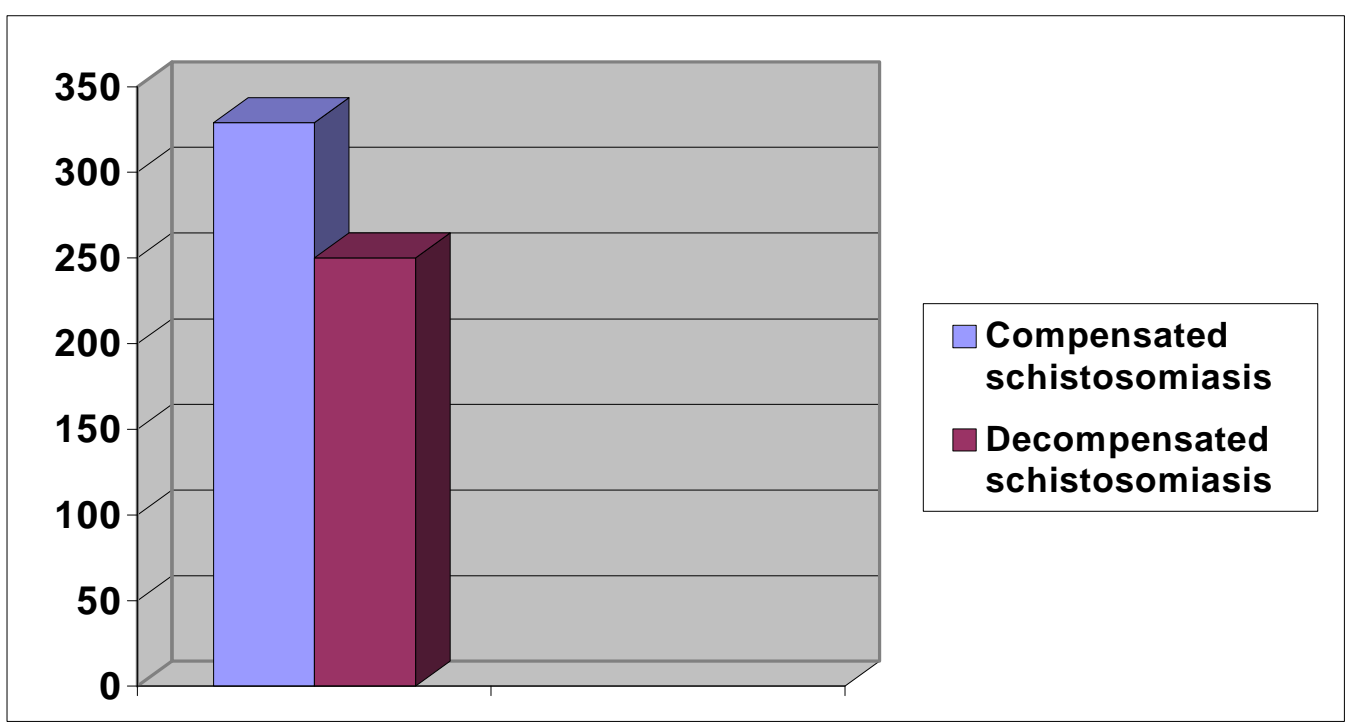

Figure (2): IL-4 in compensated and decompensated schistosomiasis.

\section{Discussion}

Our study demonstrated that, the IL-4 (Th2) was extremely significantly high in stage I where was the $(\mathrm{P}<0.001)$ and then decreases progressively to stage 3 , where was $(p<0.01)$ then, to non-significant increase in stage 4 $(\mathrm{P}>0.05)$. We could explain these changes in cytokines pattern in this group of patients by that, the Th2 (IL-4) is responsible for the initiating of the schistosomal pathology and granuloma formation, and the Th1 (IL-2) is associated with the progression of the disease. These results were in agreement with Fallon et al, who demonstrated that, IL-4 drives the development of the granulomatous response whereas IL-13 is the key profibrotic cytokine in the development of schistosoma induced hepatic fibrosis ${ }^{23}$. Moreover, IL-4 is responsible for determining granuloma size, inducing the proliferation of Th2 cytokine-producing lymphocytes ${ }^{24,25}$. Also, De Moraiset al, found that, patients with intestinal schistosomiasis typically display a mixed $\mathrm{Th} 1 / \mathrm{Th} 2$ response with higher levels of IL-4 production in comparison to acute schistosomiasis ${ }^{8}$. Additionally, high levels of the Th2 cytokines IL-4 correlate with the persistence of fibrosis following treatment with praziquantel ${ }^{26}$. Overall, the results of these studies tend to corroborate those in mice suggesting that $\mathrm{Th} 2$ cytokines, including IL-4 and IL-13, promote immunop- 
athology ${ }^{10}$. In our study we found that, the level of IL-2 (Th1) was increased progressively from stage 1 (hepatomegaly) where was $(\mathrm{P}<$ 0.05 ) to stage 4 (huge splenomegaly with shrunken liver) where was the $(\mathrm{p}<0.001)$. In accordance with our results, previous studies demonstrated that, the dynamics of IL-2 production by splenic cells of schistosoma mansoni infected mice was correlated with the intensity of hepatic granulomatous inflammation $^{27}$. This explains the progressive increasing of IL-2 from stage 1 to stage 4 of hepatic granulomatous inflammation. To study the role of the Th1 and Th2 as regarding the activity and severity of the disease, hepatosplenic schistosomiasis both compensated (without ascites) and decompensated (with ascites) groups were assayed for IL-2 (Th1) and IL-4 (Th2). The results were, extremely significant increase $(\mathrm{P}<0.001)$ in decompensated group versus compensated group as regarding (IL-2), but significant increase in compensated versus decompensated group $(\mathrm{P}<0.001)$ as regarding (IL4. This means that Th1 is responsible for progression and more severe form of the hepstosplenic schistosomiasis. These results were in agreement with, Mwatha et al, who showed that, in both mice and humans infected with schistosoma mansoni, diminished type 2 and heightened type I responses are associated with severe morbidity ${ }^{28}$. In addition, Fallon et al, showed that, more convincingly evidence from schistosoma infected humans suggest that, proinflammatory type I responses are the cause morbidity in schistosomiasis ${ }^{29}$. Moreover, data indicated that more severe form of schistosoma infection (hepatosplenomegaly) is associated with Th1 profile following in vitro stimulation with antigen ${ }^{28}$. However, the our results are in contrast to the data that demonstrated that, in context of the type1/type 2 cytokines paradigm, data from mice and humans have categorized schistosomiasis as type 2 disease, implicating type 2 responses as the cause of morbity and being detrimental to the host ${ }^{30}$. Moreover, decreased fibrosis was associated with diminished Th2 -responses and accentuated type 1 cytokines production. Additionally, mAb anti IL-4 treatment of mice tends to reduce granuloma size and fibrosis ${ }^{31}$. In this study it was reported that patients, with schistosomiasis and viral hepatitis $\mathrm{C}$ showing highly significant increase in IL-4 (Th2) $(\mathrm{P}<0.001)$ and significant increase in IL-2 $(\mathrm{P}<0.05)$ when compared with control group. Patients with schistosomiasis and chronic hepatitis B showing highly significant increase in IL-4 $(\mathrm{Th} 2)(\mathrm{P}<0.001)$ and significant increase in IL-2 $(\mathrm{P}<0.05)$ when compared with control group. This means that, in co-infected patients with schistosomiasis and viral hepatitis (chronic HCV and HBV), the Th2 was prominent than Th1. These results were in agreement with Kamal et al., who showed that, co-infected patients with schistosomiasis and viral hepatitis had high IL-4 and IL-10 (Th2 profile), whereas patients infected with chronic hepatitis alone had higher IFN- $\gamma$ and TNF- $\alpha$ ( Th1 profile) ${ }^{32}$. It was showed that, in combined schistosomiasis and chronic hepatitis, Th2 profile (IL-4) induced by schistosomiasis antagonized and down regulated the antiviral activities of Th1 cytokines, resulting in increased viral replication and more progression to fibrosis. Imbalance toward a Th2 profile at the time of acquisition of viral infection or during the acute stage of the disease may favor the faster progression to chronicity in co-infected patients ${ }^{33,34}$. In contrast to results of this study is that, Egyptian patients infected with $\mathrm{HCV}$ genotype 4 can mount HCV- specific $\mathrm{T}$ cell responses, both CD4+ and CD8+ T cellmediated, despite the prevalence of concomitant schistosomiasis ${ }^{35}$.

\section{Conclusion}

Patients with chronic schistosomiasis present a mixed profile of Th1 and Th2 cytokines. The Th2 (IL-4) was elevated in the first stage of hepstosplenic schistosomiasis and then decreased with progression of the disease while, the Th1 (IL-2) was increased with the progression of the hepatosplenic schistosomiasis from stage 1(hepatomegaly) to the stage 4 (decompensated schistosomiasis). In patients with combined schistosomiasis and chronic hepatitis the Th2 (IL-4) is the predominant cytokine versus Th1 (IL-2).

\section{References}

1- Hotez P, Savioli L, Fenwick A. Neglected tropical diseases of the Middle East and North Africa: review of their prevalence, distribution and opportunities of control. PLoSNegl Trop Dis. 2012; 6: e1475-e1482.

2- Gryseels B, Polman K, Clerinx J \&Kestens L. Human. schistosomiasis. Lancet. 2006; 368: 1106-1118. 
3- Pearce E, MacDonald A. The Immunobiology of Schistosomiasis. Nat Rev Immunol. 2002; 2: 499-511.

4- Ross A, Bartley P, Sleigh A $t$ al. Schistosomiasis. N Engl J Med. 2002; 346: 1212-1220.

5- Wynn T, Thompson R, Cheever A, MentinkKane M. Immunopathogenesis of schistosomiasis. Immunol Rev. 2004; 201: 156-167.

6- Wilson M, Mentink-Kane M, Pesce J, Ramalingam $\mathrm{T}$, Thompson R, Wynn $\mathrm{T}$. Immunopathology of schistosomiasis. Immunol Cell Biol. 2007; 85: 148-154.

7- Cheng Y, Song W, Liu W, et al. The effects of $\mathrm{T}$ cell deficiency on the development of worms and granuloma formation in mice infected with Schistosoma japonicum. Parasitol Res. 2008; 102: 1129-1134.

8- De Morais C, De Souza J, Melo $\mathrm{W}$, et al. Cytokine profile associated with chronic and acute human schistosomiasis mansoni. Mem Inst Oswaldo Cruz. 2008; 103: 561-568.

9- Teixeira-Carvalho A, Martins-Filho O, Peruhype-Magalhaes V, Silveira-Lemos D, Malaquias L, Oliveira L, et al. Cytokines, chemokine receptors, CD4 (+) CD25 $(\mathrm{HIGH}+) \mathrm{T}$-cells and clinical forms of human schistosomiasis. Acta Trop. 2008; 108(2-3):139-149.

10- Burke M, Jones, M, Gobert G, Li Y, Ellis $\mathrm{M}$, McManus D. Immunopathogenesis of human schistosomiasis. Parasite Immunology. 2009; 31, 163-176

11- Abath F, Morais C, Montenegro C, Wynn $\mathrm{T}$, Montenegro S. Immunopathogenic mechanisms in schistosomiasis: what can be learnt from human studies?. Trends Parasitol 2006; 22 (2): 85-91.

12- Conceição $M$, Argento $C$, Chagas V, Takiya C, Moura D, Silva S. Prognosis of Schistosomiasis mansoni patients infected with hepatitis B virus. Mem Inst Oswaldo Cruz. 1998; 93: 255-258.

13- El-Masry S, Lotfy M, El-Shahat M, Badra G. Serum laminin assayed by Slot-BlotELISA in patients with combined viral hepatitis C and schistosomiasis. Clin Biochem. 2006; 39: 652-657.

14- Kamal S, Turner B, He Q, Rasenack J, Bianchi L, Al Tawil A, Nooman A, Massoud M, Koziel M, Afdhal N. Progression of fibrosis in hepatitis $\mathrm{C}$ with and without schistosomiasis: Correlation with serum markers of fibrosis. Hepatology 2006; 43 : 771-779.

15- Kamal S, Rasenack J, Bianchi L, Al Tawil A, El Sayed K, Peter T, Mansour H, Ezzat W, Koziel M. Acute hepatitis C without and with Schistosomiasis: Correlation with hepatitis C-specific CD4(+) T-cell and cytokine response. Gastroenterology 2001; 121: 646-656.

16- El-Sayed H, Abaza S, Mehanna S, Winch $\mathrm{P}$. The prevalence of hepatitis $\mathrm{B}$ and $\mathrm{C}$ infections among immigrants to a newly reclaimed area endemic for Schistosoma mansoni in Sinai, Egypt. Acta Trop. 1997; 68: 229-237.

17- Angelico M, Renganathan E, Gandin C, Fathy M, Profili M, Refai W, De Santis A, Nagi A, Amin G, Capocaccia L, Callea F, Rapicetta M, Badr G, Rocchi G. Chronic liver disease in the Alexandria governorate, Egypt: contribution of schistosomiasis and hepatitis virus infections. J. Hepatol. 1997; 26: 236-243.

18- Van-Lume D, Albuquerque Mde F, Souza A, Domingues A, Lopes E, Morais C, Montenegro S. Association between Schistosomiasis mansoni and hepatitis C: systematic review. Rev Saude Publica 2013; 47: 414-424.

19- Li Y, Chen D, Ross A, Burke M, Yu X, Li R, et al. Severe hepatosplenic schistosomiasis: Clinicopathologic study of 102 cases undergoing splenectomy. Hum Pathol. 2011; 42: 111-119.

20- El-Esnawy N, Al-Herrawy A. Seroprevalence of certain hepatitis viruses among Egyptian workers infected with schistosomiasis. J. Egypt Public Health Assoc. 2000; 75: 357-366.

21- Abdel-Rahman M, El-Sayed M, El Raziky M, Elsharkawy A, El-Akel W, Ghoneim $\mathrm{H}$, et al. Co infection with hepatitis $\mathrm{C}$ virus and schistosomiasis: Fibrosis and treatment response. World J. Gastroenterol. 2013; 19: 2691-2696.

22- Da Silva L, Chieffi P, Carrilho F. Schistosomiasis mansoni-clinical features. Gastroenterol Hepatol. 2005; 28 (1):30-39.

23- Fallon P, Richardson E, McKenzie G, McKenzie A. Schistosome infection of transgenic mice defines distinct and contrasting pathogenic roles for IL- 4 and IL- 13: IL- 13 is a profibrotic agent. J. Immunol. 2000; 164: 2585-2591. 
24- Hirata M, Kage M, Hara T, Yoneda $Y$, Zhang M, Fukuma T. Schistosoma japonicum egg granuloma formation in the interleukin - 4 or interferon- $\gamma$; deficient host. Parasite Immunol. 2001; 23: 271-280.

25- Rumbley C, Sugaya H, Zekavat S, El Refaei M, Perrin P, Phillips S. Activated eosinophils are the major source of Th2 $\square$ associated cytokines in the schistosome granuloma. J. Immunol. 1999; 162: 1003-1009.

26- Coutinho H, Acosta L, Wu H, et al . Th2 cytokines are associated with persistent hepatic fibrosis in human Schistosoma japonicum infection. J. Infect Dis. 2007; 195: 288-295.

27-Yamashita T, Boros D. IL-4 influences IL-2 production and granulomatous inflammation in murine schistosomiasis mansoni. J. Immunol. 1992, 149 (11): 3659-3664.

28- Mwatha J, Kimani G, Kamau T, Mbugua G, Ouma J, Mumo J, et al. High levels of TNF, soluble TNF receptors, soluble ICAM1, and IFN-gamma, but low levels of IL-5, are associated with hepatosplenic disease in human schistosomiasis mansoni. J. Immunol. 1998; 160:1992-1999.

29- Fallon P. Immunopathology of schistosomiasis: Acautionary tale of mice and men. Immunol Today. 2000; 21: 29-35.
30- Wynn T, Cheever A. Cytokines regulation of granuloma formantion in schistosomiasis. Curr Opin Immunol. 1995; 7: 505-511.

31- Cheever A, Williams M, Wynn $T$, Finkelman F, Seder R, Cox T, et al. AntiIL-4 treatment of Schistosoma mansoniinfected mice inhibits development of $\mathrm{T}$ cells and non-B, non- $\mathrm{T}$ cells expressing Th2 cytokines while decreasing egginduced hepatic fibrosis. J. Immunol. 1994, 153: 753-759.

32- Kamal S, Madwar M, Bianchi L. Clinical, virological, and histopathological features: Long-term follow-up in patients with chronic hepatitis C coinfected with Schistosoma mansoni. Liver. 2001; 20: 281-289.

33- Angelico M, Renganathan E, Gandin C. Chronic liver disease in Alexandria governorate, Egypt: contribution of schistosomiasis and hepatitis virus infections. J. Hepatol. 1997; 26: 236-243.

34- Pereira L, Melo M, Saleh M. Hepatitis C virus infection in Schistosomiasis mansoni in Brazil. J. Med Virol. 1995; 45: 423-428.

35- Elrefaei M, EL-sheikh N, Kamal K, Cao $\mathrm{H}$ : Analysis of $\mathrm{T}$ cell responses against hepatitis $\mathrm{C}$ virous genotype 4 in Egypt. J. hepatol. 2004; 40 (2): 313-318. 